\title{
The Seductive Allure of Cargo Cult Computationalism
}

Micah Allen $1,2,3$

${ }_{1}$ Aarhus Institute of Advanced Studies, Aarhus University, Aarhus, Denmark

${ }_{2}$ Center of Functionally Integrative Neuroscience, Aarhus University, Aarhus, Denmark

${ }_{3}$ Cambridge Psychiatry, University of Cambridge, Cambridge, UK

This paper is a commentary on Bruineberg, Dolega, Dewhurst, and Baltieri (forthcoming). The Emperor's New Markov Blankets. Behavioral and Brain Sciences.

\begin{abstract}
Bruineberg and colleagues report a striking confusion, in which the formal Bayesian notion of a "Markov Blanket" has been frequently misunderstood and misapplied to phenomena of mind and life. I argue that misappropriation of formal concepts is pervasive in the "predictive processing" literature, and echo Richard Feynman in suggesting how we might resist the allure of cargo cult computationalism.
\end{abstract}

\section{Main Text}

"The first principle is that you must not fool yourself - and you are the easiest person to fool" - Richard Feynman, 1974

In their compelling arguments, Bruineberg and colleagues reveal how the mathematical, Bayesian construct of a "Markov blanket" has become a go-to explanans in topics as far-reaching as neuroscience, sociology, the philosophy of mind, and epistemology (Bruineberg et al., 2021). Through careful analyses of the prerequisite formalisms, they reveal how many of these works have confused a realist understanding of Markov blankets with their actual properties as defined by formal information and probability theory. A consequence of this confusion is that Markov blankets are ascribed properties they do not possess, and are frequently leveraged to explain phenomena for which they have little direct relevance. Indeed, it has been argued Markov blankets can demarcate the definition of life (Kirchhoff et al., 2018), can be used to construct a kind of Asimovian psychohistory (Allen, 2018; Ramstead et al., 2018; Veissière et al., 2019), and even extend cognition to plants (Calvo \& Friston, 2017). Bruineberg and colleagues argue that these and many similar arguments fail to fully capture what is and is not offered by Markov blankets, and go on to proffer a helpful framework for understanding and applying Markovian concepts to cognitive phenomena, based on an informed analysis of their actual formal properties.

As I read the target article, I could not help but think of the late Richard Feynman's now infamous remarks, delivered to the Caltech class of '74, in which he warned of the dangers of "cargo cult science" (Feynman, 1974). Prior to the commencement address, Feynman had visited the Esalen Institute, a well-known nexus for holistic thinking and "alternative" science. He recounted how, to his surprise, many of the advocates of esoteric mysticism and parapsychology he met there inevitably presented their ideas as scientific, 
when they were clearly anything but. But perhaps more ominous, he also remarked how many of the styles of argumentation made surface appeals to the scientific method struck him as no different in kind from similar examples observed in mainstream fields of psychology, neuroscience, and even physics. Feynman dubbed these trends as "cargo cult science", and outlined a few key points through which to identify and ultimately avoid such cults.

What then, is cargo cult science? Cargo cults were first described during the second world war, when Melanesian and other Pacific Islanders sought to capture the technological and economic powers of the Allied and Japanese forces who would frequently land there to trade cargo for goods. Convinced by their spiritual leaders that such awesome wealth and technological power would be shared with them, the islands began to form ritualistic cults which fetishized various outward characteristics of the foreign powers. By wearing their uniforms, making totem rifles, and marching up and down the beach in a similar manner, these cults hoped that the gods would also bestow upon them the same powers of those they imitated.

Much like these namesake cults, Feynman described cargo cult science as generally being that which sought the appeal and authority of the scientific method, but which failed to live up to its standard in several key regards. First and foremost among the qualities lacking in cargo cult science was a radical commitment to scientific integrity, which he described as:

"... a principle of honest thought... a kind of leaning over backwards... you should report everything you think might make it invalid - not only what you think might be right about it... If you make a theory ... then you must also put down all the facts that disagree with it..."

Feynman goes on to define several other key characteristics of cargo cult science. These include, 1) a failure to engage critically with both the strengths and faults of any theoretical or empirical postulate, 2) an insistence on doing pseudo-experiments which could not have come out otherwise, 3) a kind of ahistorical perspective in which key data points or advances are overlooked or ignored entirely, and crucially, 4) a surface appeal to explanatory devices or scientific concepts without a deeper engagement.

In recent years, I have observed a steady growth of these sorts of errors in the predictive processing literature. Chief among these is an almost casual, devil-may-care appropriation of computational concepts and the outward appearances of computationalism without a deeper engagement. This takes many forms: for example, the description of pseudo-equations as Bayesian "models"1, or the frequent introduction of new psychological "theories" rehashing concepts such as "priors", "prediction errors", "precision", or "Markov Blankets" as explanatory in and of themselves ${ }^{2}$. A more recent trend is found in the burgeoning volume of so-called "in silico"

\footnotetext{
${ }^{1}$ See, e.g., "This model is formalized by the following equation,

$\mathrm{P}($ Mommy|Interoception, Exteroception $) \propto \mathrm{P}($ Mommy $) \mathrm{x}$ $\mathrm{P}$ (Interoception|Mommy) x P(Exteroception|Mommy)", from Atzil et al (2018). See also my own equally egregious example in Allen \& Tsakiris (2018).

${ }^{2}$ Aptly dubbed the "Bayes Glaze" by anonymous twitter commentator, @Neuroskeptic
} 
demonstrations, in which an off the shelf Markovian model is merely re-parameterized and then described as a new "model" of some complex phenomenon - emotion (Hesp et al., 2021), ecological niche construction (Bruineberg et al., 2018), interoception (Allen et al., 2019), or even life itself all being salient examples (Friston, 2013). Typically such demonstrations involve minimal reshaping of the underlying models themselves, which is remarkable considering the breadth of topics to which they are applied.

A similar error can be found frequently in empirical studies of various psychological phenomena - a kind of computational prestidigitation, in which a construct such as "precision" is appealed to, an experiment is conducted, and then a paper produced which proudly claims to have provided evidence for the underlying computational theory. A salient example could be, i.e., an experiment in which attention to the body is manipulated, and some consequent alteration in an ambiguous data feature is observed, which is then interpreted unambiguously as 'evidence for precision weighting' (Petzschner et al., 2019). While predictive processing will certainly claim the credit here, it seems obvious that in the absence of an actual, robust, model fitting procedure, just about any psychological or computational theory could be levied to explain the obtained results. This trick is pervasive in a new flood of psychological and neural experiments in which attention, expectation, confidence, or other concepts with a face-value cousin in the formal theory of predictive processing can be found and manipulated, a high impact paper produced, and no attempt at true falsification is made.

The issue is of course that across all of these examples there is a failure to engage directly with the underlying formal concepts themselves, and a commensurate failure to apply appropriate computational steps to enable falsification and ultimately, safeguard against pseudoscience. Critical steps for establishing Feynman's radical honesty - such as model cross-validation, model falsification, or even fitting to empirical data at all - crucial for preventing overfitting - are few and far between (Palminteri et al., 2017; Wilson \& Collins, 2019). It is salient then that in the very same lecture, Feynman famously warned of his 'first principle'. Too many of us - the author included - are at risk of violating this principle, likely in hopes of riding the Bayesian wave to the promised land of high impact computational neuroscience papers. I applaud Bruineberg and colleagues for showing us how to leave the cargo cult behind. 


\section{References}

Allen, M. (2018). The foundation: Mechanism, prediction, and falsification in Bayesian enactivism: Comment on "Answering Schrödinger's question: A free-energy formulation" by Maxwell James Désormeau Ramstead et al. Physics of Life Reviews, 24, 17-20. https://doi.org/10.1016/j.plrev.2018.01.007

Allen, M., Levy, A., Parr, T., \& Friston, K. J. (2019). In the Body's Eye: The Computational Anatomy of Interoceptive Inference. BioRxiv, 603928. https://doi.org/10.1101/603928

Allen, M., \& Tsakiris, M. (2018). The body as first prior: Interoceptive predictive processing and the primacy. The Interoceptive Mind: From Homeostasis to Awareness, 27.

Atzil, S., Gao, W., Fradkin, I., \& Barrett, L. F. (2018). Growing a social brain. Nature Human Behaviour, 2(9), 624-636. https://doi.org/10.1038/s41562-018-0384-6

Bruineberg, J., Dolega, K., Dewhurst, J., \& Baltieri, M. (2021). The Emperor's New Markov Blankets. Behavioral and Brain Sciences, 1-63. https://doi.org/10.1017/S0140525X21002351

Bruineberg, J., Rietveld, E., Parr, T., van Maanen, L., \& Friston, K. J. (2018). Free-energy minimization in joint agent-environment systems: A niche construction perspective. Journal of Theoretical Biology, 455, 161-178. https://doi.org/10.1016/j.jtbi.2018.07.002

Calvo, P., \& Friston, K. (2017). Predicting green: Really radical (plant) predictive processing. Journal of the Royal Society Interface, 14(131), 20170096. https://doi.org/10.1098/rsif.2017.0096

Feynman, R. P. (1974). Cargo cult science. Engineering and Science, 37(7), 10-13.

Friston, K. (2013). Life as we know it. Journal of The Royal Society Interface, 10(86), 20130475. https://doi.org/10.1098/rsif.2013.0475

Hesp, C., Smith, R., Parr, T., Allen, M., Friston, K. J., \& Ramstead, M. J. D. (2021). Deeply Felt Affect: The Emergence of Valence in Deep Active Inference. Neural Computation, 33(2), 398-446. https://doi.org/10.1162/neco_a_01341

Kirchhoff, M., Parr, T., Palacios, E., Friston, K., \& Kiverstein, J. (2018). The Markov blankets of life: Autonomy, active inference and the free energy principle. Journal of The Royal Society Interface, 15(138), 20170792. https://doi.org/10.1098/rsif.2017.0792

Palminteri, S., Wyart, V., \& Koechlin, E. (2017). The Importance of Falsification in Computational Cognitive Modeling. Trends in Cognitive Sciences, 21(6), 425-433. https://doi.org/10.1016/j.tics.2017.03.011

Petzschner, F. H., Weber, L. A., Wellstein, K. V., Paolini, G., Do, C. T., \& Stephan, K. E. (2019). Focus of attention modulates the heartbeat evoked potential. Neurolmage, 186, 595-606. https://doi.org/10.1016/j.neuroimage.2018.11.037

Ramstead, M. J. D., Badcock, P. B., \& Friston, K. J. (2018). Answering Schrödinger's question: A free-energy formulation. Physics of Life Reviews, 24, 1-16. https://doi.org/10.1016/j.plrev.2017.09.001

Veissière, S. P. L., Constant, A., Ramstead, M. J. D., Friston, K. J., \& Kirmayer, L. J. (2019). Thinking Through Other Minds: A Variational Approach to Cognition and Culture. Behavioral and Brain Sciences, 1-97. https://doi.org/10.1017/S0140525X19001213

Wilson, R. C., \& Collins, A. G. (2019). Ten simple rules for the computational modeling of behavioral data. ELife, 8, e49547. https://doi.org/10.7554/eLife.49547 